\title{
Fast photolysis of carbonyl nitrates from isoprene
}

\author{
J.-F. Müller ${ }^{1}$, J. Peeters ${ }^{2}$, and T. Stavrakou ${ }^{1}$ \\ ${ }^{1}$ Belgian Institute for Space Aeronomy, Avenue Circulaire 3, 1180 Brussels, Belgium \\ ${ }^{2}$ Department of Chemistry, University of Leuven, 3001 Heverlee, Belgium \\ Correspondence to: J.-F. Müller (jfm@aeronomie.be)
}

Received: 7 October 2013 - Published in Atmos. Chem. Phys. Discuss.: 28 November 2013

Revised: 6 February 2014 - Accepted: 8 February 2014 - Published: 11 March 2014

\begin{abstract}
Photolysis is shown to be a major sink for isoprene-derived carbonyl nitrates, which constitute an important component of the total organic nitrate pool over vegetated areas. Empirical evidence from published laboratory studies on the absorption cross sections and photolysis rates of $\alpha$-nitrooxy ketones suggests that the presence of the nitrate group (i) greatly enhances the absorption cross sections and (ii) facilitates dissociation to a point that the photolysis quantum yield is close to unity, with $\mathrm{O}-\mathrm{NO}_{2}$ dissociation as a likely major channel. On this basis, we provide new recommendations for estimating the cross sections and photolysis rates of carbonyl nitrates. The newly estimated photo rates are validated using a chemical box model against measured temporal profiles of carbonyl nitrates in an isoprene oxidation experiment by Paulot et al. (2009). The comparisons for ethanal nitrate and for the sum of methacrolein- and methyl vinyl ketone nitrates strongly supports our assumptions of large cross-section enhancements and a near-unit quantum yield for these compounds. These findings have significant atmospheric implications: the photorates of key carbonyl nitrates from isoprene are estimated to be typically between $\sim 3$ and 20 times higher than their sink due to reaction with $\mathrm{OH}$ in relevant atmospheric conditions. Moreover, since the reaction is expected to release $\mathrm{NO}_{2}$, photolysis is especially effective in depleting the total organic nitrate pool.
\end{abstract}

\section{Introduction}

Photolysis is recognized as a significant atmospheric sink for most oxygenated compounds generated in the oxidation of prominent non-methane volatile organic compounds such as isoprene. However, direct laboratory measurements of the photodissociation parameters are most often lacking, and model estimations must rely on analogies with structurally similar compounds for which those parameters are known from experiment. In the case of multifunctional organic compounds, it is common practice even in the most detailed chemical mechanisms (Saunders et al., 2003; Capouet et al., 2008) to treat each functionality independently of the other functional groups, i.e. the total photorate is calculated as a sum of independent contributions. Exceptions are provided by the cases of $\alpha$-dicarbonyls, for which both cross section and quantum yield data are available (Atkinson et al., 2006; Sander et al., 2011), and $\alpha$-nitrooxy ketones, for which cross sections were measured by Roberts and Fajer (1989) and Barnes et al. (1993). In both cases, interactions between the two neighbouring functional groups appear to strongly enhance the absorption cross sections. A similar effect is expected for $\alpha$-nitrooxy aldehydes, but is not taken into account in models due to a lack of data.

Regarding the photodissociation quantum yields of carbonyl nitrates, quite arbitrary assumptions are currently made in chemical mechanisms (Saunders et al., 2003; Xie et al., 2013) resulting in potentially large errors in the photolysis rates and product distributions. The difficulty resides in the large disparity between the quantum yield of monofunctional nitrates, usually assumed to be unity, independent of wavelength, and the quantum yield of carbonyls, which is very variable between different compounds and frequently very low at atmospherically relevant wavelengths (i.e. above ca. $310 \mathrm{~nm}$ ) (Atkinson et al., 2006). However, recent photorate measurements of several $\alpha$-nitrooxy ketones in the laboratory (Suarez-Bertoa et al., 2012) appear to imply near-unit quantum yields for these compounds, and cast new light on the photodissociation process. Note that near-unit quantum yield in the photolysis of bifunctional carbonyls is not a novelty in itself: recent theoretical work (Peeters et al., 2009; 
Table 1. Isoprene-derived carbonyl nitrates considered in this study.

\begin{tabular}{ll}
\hline \multicolumn{1}{c}{ Formula } & \multicolumn{1}{c}{ Notation } \\
\hline \multicolumn{2}{c}{ nitrooxy ketones } \\
$\mathrm{CH}_{3} \mathrm{COCH}_{2}\left(\mathrm{ONO}_{2}\right)$ & $\mathrm{NOA}$ \\
$\mathrm{CH}_{3} \mathrm{COCH}\left(\mathrm{ONO}_{2}\right) \mathrm{CH}_{2} \mathrm{OH}$ & $\mathrm{MVKNO} 3$ \\
$\mathrm{CH}_{3} \mathrm{COCH}(\mathrm{OH}) \mathrm{CH}_{2} \mathrm{ONO}_{2}$ & $\mathrm{HMVKANO} 3$ \\
\hline \multicolumn{2}{c}{ nitrooxy aldehydes } \\
$\mathrm{OCHCH}_{2}\left(\mathrm{ONO}_{2}\right)$ & $\mathrm{NO}_{3} \mathrm{CH}_{2} \mathrm{CHO}$ \\
$\left.\mathrm{OCHC}^{2} \mathrm{CH}_{3}\right)\left(\mathrm{ONO}_{2}\right) \mathrm{CH}_{2} \mathrm{OH}$ & $\mathrm{MACRNO}^{2}$ \\
\hline & \\
$\mathrm{OCHCH}=\mathrm{C}\left(\mathrm{CH}_{3}\right) \mathrm{CH}_{2} \mathrm{ONO}_{2}$ & $\mathrm{NC} 4 \mathrm{CHO}$ \\
\hline
\end{tabular}

Peeters and Müller, 2010) confirmed by laboratory experiments (Wolfe et al., 2012) has shown that isoprene-derived hydroperoxy enals (HPALDs) photodissociate with a quantum yield of unity, i.e. more than two orders of magnitude higher than in the photolysis of monofunctional enones and enals such as methacrolein (MACR).

Furthermore, photolysis was shown (theoretically and experimentally) to result in the breakup of the weakly bonded $-\mathrm{OOH}$ function and formation of $\mathrm{OH}$ radical. This example demonstrates that photon absorption by one chromophore in a multifunctional compound might cause rearrangement and dissociation in another part of the same molecule that is in a sufficiently weakly bonded functional group.

Examples of such groups are the hydroperoxide and peracid groups, but also - of relevance here - the nitrooxy group, with its $\mathrm{RO}-\mathrm{NO}_{2}$ bond dissociation energy of only about $40 \mathrm{kcal} \mathrm{mol}^{-1}$, similar to $\mathrm{RO}-\mathrm{OH}$.

Carbonyl nitrates constitute a sizeable fraction of the total pool of organic nitrates $\left(\mathrm{RONO}_{2}\right)$ over regions dominated by biogenic NMVOC emissions (Beaver et al., 2012). The role of organic nitrates as $\mathrm{NO}_{\mathrm{x}}$ reservoirs or sinks, and their importance to ozone production, has been recognized (Perring et al., 2013). Differences in the model representation of their chemistry are estimated to cause substantial differences in model simulations of tropospheric ozone (Paulot et al., 2012) and other oxidants such as the hydroxyl radical $\mathrm{OH}$. The photochemical lifetime and $\mathrm{NO}_{\mathrm{x}}$ recycling of these nitrates are therefore key parameters needed for an accurate description of tropospheric chemistry. Of particular relevance are several carbonyl nitrates known to be isoprene oxidation products identified in laboratory experiments (Paulot et al., 2009; Kwan et al., 2012) as well as in the field (Beaver et al., 2012; Perring et al., 2013). These compounds are listed in Table 1 along with their notation in the Master Chemical Mechanism (MCM) version 3.2 (Saunders et al., 2003). Note that the isomers MVKNO3, HMVKANO3 and MACRNO3 cannot be distinguished using current experimental techniques (Paulot et al., 2009; Beaver et al., 2012).
The $\alpha$-nitrooxy carbonyls MVKNO3 and MACRNO3 are major second-generation nitrates formed in the oxidation of isoprene by $\mathrm{OH}$, primarily through the $\mathrm{OH}-$ and $\mathrm{O}_{3}$ oxidation of the $\beta$-hydroxy-nitrates from isoprene (ISOPBO 2 and ISOPDO2 in MCMv3.2). HMVKANO3 is a comparatively more minor nitrooxy ketone (Paulot et al., 2009). NC4CHO is a first-generation nitrate generated in the oxidation of isoprene by $\mathrm{NO}_{3}$. $\alpha$-Nitrooxy acetone (NOA) is likely the most abundant individual carbonyl nitrate (Beaver et al., 2012), due to its relatively long photochemical lifetime and because it is produced (as a second- or third-generation product) in both the $\mathrm{OH}-$ and $\mathrm{NO}_{3}$-initiated oxidation of isoprene (Xie et al., 2013).

In current mechanisms, low quantum yields are generally assumed for carbonyl nitrates $(<0.3$ above $310 \mathrm{~nm}$ for NOA in MCMv3.2), and NOA is often used as model compound for most $\alpha$-nitrooxy carbonyls (including the aldehyde nitrates), despite the much higher cross sections of (monofunctional) aldehydes compared to ketones in the atmospherically relevant wavelength range (Atkinson et al., 2006). As a result, the role of photolysis is very likely strongly underestimated in models for those compounds. An improved assessment of this role is the main purpose of this study.

New recommendations for the estimation of the cross sections and photolysis quantum yields of carbonyl nitrates are presented in the next sections, based on the available evidence. A detailed isoprene oxidation mechanism largely based on MCMv3.2 is used in Sect. 4 to evaluate the impact of the new photorate estimation against the observed temporal evolution of products in the isoprene oxidation experiment at high $\mathrm{NO}_{\mathrm{x}}$ presented by Paulot et al. (2009). To that end, the rates of critical reactions of organic nitrates will be also reevaluated, given their importance in determining the temporal evolution of isoprene oxidation products. The atmospheric implications and conclusions of the new findings will be presented in Sects. 5 and 6 .

\section{Cross sections}

We define the cross-section enhancement $r_{\mathrm{nk}}$ of a carbonyl nitrate as the ratio of its absorption cross section $\left(S_{\mathrm{nk}}\right)$ to the sum of the cross sections of closely similar monofunctional compounds, namely a ketone $\mathrm{k}$ and a nitrate $\mathrm{n}\left(S_{\mathrm{n}}\right.$ and $\left.S_{\mathrm{k}}\right)$ :

$r_{\mathrm{nk}}=\frac{S_{\mathrm{nk}}}{S_{\mathrm{n}}+S_{\mathrm{k}}}$

Ideally, the monofunctional nitrate $(\mathrm{n})$ should be the compound nk in which the ketone group is replaced by $\mathrm{CH}_{2}$, and the ketone $(\mathrm{k})$ should be the compound nk in which the nitrate group is replaced by a hydrogen. Note that as a general rule, $S_{\mathrm{n}} \ll S_{\mathrm{k}}$ at atmospherically relevant wavelengths $(>310 \mathrm{~nm})$.

The enhancement ratio $r_{\mathrm{nk}}$ is represented in Fig. 1 for three $\alpha$-nitrooxy ketones, namely $\alpha$-nitrooxy acetone, 


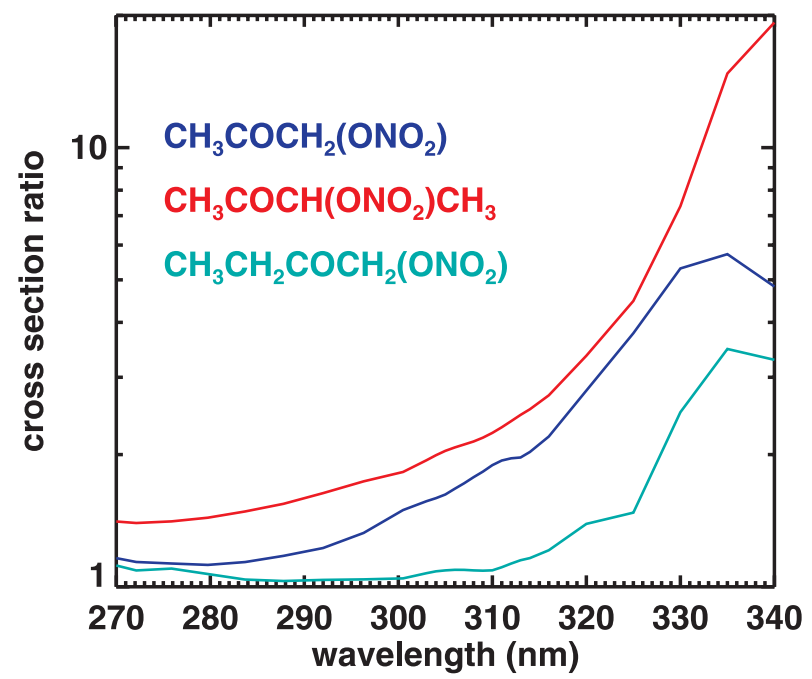

Fig. 1. Cross section enhancement $\left(r_{\mathrm{nk}}\right)$ of several nitrooxy ketones, i.e. ratio of their cross section $\left(S_{\mathrm{nk}}\right)$ to the sum of the cross sections of structurally similar monofunctional compounds $S_{\mathrm{n}}+S_{\mathrm{k}}$.

3-nitrooxy-2-butanone and 1-nitrooxy-2-butanone, for which cross-section measurements are available from Barnes et al. (1993). The cross sections of the following monofunctional compounds (obtained from Atkinson et al. (2006)) were used: acetone and $n$-propyl nitrate (for NOA), methyl ethyl ketone and $i$-propyl nitrate (for 3-nitrooxy-2-butanone), methyl ethyl ketone and $n$-propyl nitrate (for 1-nitrooxy-2butanone). Note that $i$-propyl nitrate was used due to lack of data for $\mathrm{CH}_{3} \mathrm{CH}_{2} \mathrm{CH}\left(\mathrm{ONO}_{2}\right) \mathrm{CH}_{3}$, which should not be of any consequence except at the shorter wavelengths, where $S_{\mathrm{n}}$ becomes dominant. Although it is difficult to assign error bars to the ratios shown in Fig. 1, the largest uncertainty likely concerns the cross sections $\left(S_{\mathrm{nk}}\right)$ of the nitrooxy ketones. The uncertainty was estimated by Barnes et al. (1993) to be larger $(80 \%)$ for NOA (due to its thermal instability) and for 1-nitrooxy-2-butanone (due to its relatively low vapour pressure) than for 3-nitrooxy-2-butanone (20\%), but such a large difference between the two butanones does not appear justified by recent vapour pressure estimation methods (Compernolle et al., 2011). Note that the cross sections of NOA measured in a previous laboratory study (Roberts and Fajer, 1989) were only slightly lower than those of Barnes et al. (1993): by about $12 \%$ on average between 310 and $330 \mathrm{~nm}$.

Figure 1 clearly demonstrates a significant enhancement in the cross sections induced by the interaction between the two functional groups. The effect is especially pronounced in the cases of NOA and 3-nitrooxy-2-butanone, with $r_{\mathrm{nc}}>5$ for both compounds around $330 \mathrm{~nm}$. Since the enhancement is largest at the higher wavelengths, where absorption by the nitrate chromophore is very small, it is clearly the absorption by the carbonyl chromophore which is enhanced due to the neighbouring nitrate group. This high sensitivity is expected: the forbidden nature of the $\left(n, \pi^{*}\right)$ transition in carbonyls causes the transition probability (governed by the overlap of the ground state and excited state wave functions) to be very small but also very sensitive to even small changes in these wave functions, e.g. due to inductive or polarization effects by a neighbouring group such as $\mathrm{ONO}_{2}$, due to its high electron affinity $\left(E_{\mathrm{a}}=3.94 \mathrm{eV}\right)$. It follows that the enhancement seen for $\alpha$-nitrooxy ketones is very likely a common feature for all $\alpha$-nitrooxy carbonyls.

Given the absence of experimental data for $\alpha$-nitrooxy aldehydes, we propose to calculate their absorption cross sections $\left(S_{\text {na }}\right)$ following

$S_{\mathrm{na}}=\left(S_{\mathrm{n}}+S_{\mathrm{a}}\right) \cdot r_{\mathrm{nk}}$,

where $S_{\mathrm{n}}$ and $S_{\mathrm{a}}$ are measured cross sections of a monofunctional nitrate and a monofunctional carbonyl both structurally similar to the nitrooxy aldehyde under consideration, and $r_{\mathrm{nk}}$ is the enhancement ratio (Eq. 1) of a nitrooxy ketone (nk) most similar to na. This procedure is illustrated in Fig. 2 for the case of two isoprene-derived nitrooxy aldehydes: $\mathrm{NO}_{3} \mathrm{CH}_{2} \mathrm{CHO}$ and MACRNO3 (cf. Table 1). The monofunctional compounds used in this estimation are acetaldehyde and ethyl nitrate (for ethanal nitrate) and $i$-butyraldehyde and tert-butyl nitrate (for MACRNO3). The enhancement ratios of NOA and 3-nitrooxy-2-butanone (Fig. 1) were used for ethanal nitrate and MACRNO3, respectively. The impact of the cross-section enhancement on the photolysis rates $(J$ in $\mathrm{s}^{-1}$ ) can be calculated with

$J=\int \sigma(\lambda) \cdot q(\lambda) \cdot I(\lambda) d \lambda$,

with $\lambda$ the wavelength $(\mathrm{nm}), \sigma(\lambda)\left(\mathrm{cm}^{2}\right.$ molec. $\left.^{-1}\right)$ and $q(\lambda)$ the cross section and quantum yield, and $I(\lambda)$ the actinic flux (quanta $\mathrm{cm}^{-2} \mathrm{~s}^{-1} \mathrm{~nm}^{-1}$ ). Assuming wavelengthindependent quantum yields, and using the Tropospheric Ultraviolet and Visible (TUV) model from NCAR (Madronich, 1993) (for overhead sun, 348 DU ozone), the $J$ values of $\mathrm{NO}_{3} \mathrm{CH}_{2} \mathrm{CHO}$ and MACRNO3 are increased by factors of about 3 and 4, respectively, compared to a calculation using $S_{\mathrm{na}}=\left(S_{\mathrm{n}}+S_{\mathrm{a}}\right)$.

The inductive effects of a nitrate group are expected to decrease when the distance between the functional groups increases, as observed, for example, in the well-documented effect of $\mathrm{ONO}_{2}$ on neighbouring $\mathrm{C}-\mathrm{H}$ bonds (Neeb, 2000). In the absence of experimental data for $\beta$-nitrooxy carbonyls, we will assume that their cross sections are also significantly affected by the presence of the nitrate group, if only more moderately (assumed factor of 2 increase).

Note that the presence of a hydroxy group (as often found in isoprene-derived nitrates) is known to also have a significant, although variable, effect on the cross sections of both carbonyls (Messaadia et al., 2012) and nitrates (Roberts and Fajer, 1989). This effect will be generally neglected here for the sake of simplicity, although its possible significance will be briefly discussed in Sect. 4.4. 


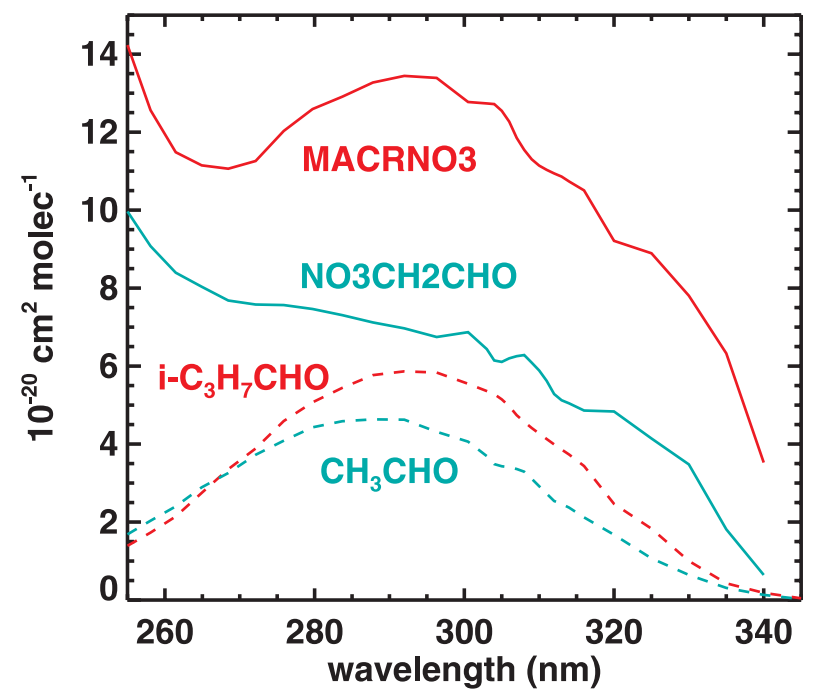

Fig. 2. Cross sections of acetaldehyde and $i$-butyraldehyde (dashed lines) recommended by Atkinson et al. (2006), and cross sections of ethanal nitrate $\left(\mathrm{NO}_{3} \mathrm{CH}_{2} \mathrm{CHO}\right)$ and MACRNO3 (cf. Table 1) estimated using Eq. (2) (solid lines).

Although very uncertain, considering the wide range of enhancement ratios observed for different nitrooxy ketones (Fig. 1), the high photorates implied by the procedure above in combination with the quantum yield estimates discussed in the next section appear consistent with the nitrooxy carbonyl measurements in the isoprene oxidation experiment of Paulot et al. (2009), as shown in Sect. 4.

\section{Quantum yields}

Using high-pressure Xenon arc lamps as the irradiation source in the indoor simulation chamber CESAM, SuarezBertoa et al. (2012) determined the photolysis rates of three $\alpha$-nitrooxy ketones, including two compounds ( $\alpha$-nitrooxy acetone and 3-nitrooxy-2-butanone) for which the absorption cross sections are known (Barnes et al., 1993). On this basis, near-unit quantum yields were inferred for these compounds (Suarez-Bertoa et al., 2012). Using Eq. (3) with the lamp spectrum and $\mathrm{NO}_{2}$ photolysis rate given in Suarez-Bertoa et al. (2012), we estimate the average quantum yield to be 0.9 for NOA and 0.75 for 3-nitrooxy-2-butanone, with an estimated error of ca. 0.2. The value of 0.9 is a factor of 4 higher than the MCMv3.2 averaged quantum yield for NOA, weighted by the cross section and actinic flux for overhead sun, surface conditions. Also, for comparison, the (weighted) average quantum yield of the simple ketones acetone (Blitz et al., 2004) and methyl ethyl ketone (Baeza-Romero et al., 2005 ) are 0.06 and 0.25 , respectively. Even much lower values $(<0.01)$ were determined for enones and enals, such as methyl vinyl ketone (MVK) and methacrolein (MACR) (Sander et al., 2011; Pinho et al., 2005).
Table 2. Isoprene-derived intermediates discussed in the text.

\begin{tabular}{|c|c|}
\hline Formula & Notation \\
\hline \multicolumn{2}{|l|}{ isoprenyl hydroxyperoxy radicals } \\
\hline $\mathrm{HOCH}_{2} \mathrm{C}\left(\mathrm{CH}_{3}\right)=\mathrm{CHCH}_{2} \mathrm{O}_{2}$ & ISOPAO2 \\
\hline $\mathrm{CH}_{2}=\mathrm{CHC}\left(\mathrm{CH}_{3}\right)\left(\mathrm{O}_{2}\right) \mathrm{CH}_{2} \mathrm{OH}$ & ISOPBO2 \\
\hline $\mathrm{HOCH}_{2} \mathrm{CH}=\mathrm{C}\left(\mathrm{CH}_{3}\right) \mathrm{CH}_{2} \mathrm{O}_{2}$ & ISOPCO2 \\
\hline $\mathrm{CH}_{2}=\mathrm{C}\left(\mathrm{CH}_{3}\right) \mathrm{CH}\left(\mathrm{O}_{2}\right) \mathrm{CH}_{2} \mathrm{OH}$ & ISOPDO2 \\
\hline \multicolumn{2}{|c|}{ peroxy radicals from isoprenyl hydroxy-nitrates } \\
\hline $\mathrm{HOCH}_{2} \mathrm{C}\left(\mathrm{CH}_{3}\right)\left(\mathrm{O}_{2}\right) \mathrm{CH}(\mathrm{OH}) \mathrm{CH}_{2}\left(\mathrm{ONO}_{2}\right)$ & INAO2 \\
\hline $\mathrm{HOCH}_{2} \mathrm{C}\left(\mathrm{ONO}_{2}\right)\left(\mathrm{CH}_{3}\right) \mathrm{CH}\left(\mathrm{O}_{2}\right) \mathrm{CH}_{2} \mathrm{OH}$ & INB1O2 \\
\hline $\mathrm{HOCH}_{2} \mathrm{CH}\left(\mathrm{O}_{2}\right) \mathrm{C}\left(\mathrm{CH}_{3}\right)(\mathrm{OH}) \mathrm{CH}_{2}\left(\mathrm{ONO}_{2}\right)$ & INCO2 \\
\hline $\mathrm{HOCH}_{2} \mathrm{C}\left(\mathrm{O}_{2}\right)\left(\mathrm{CH}_{3}\right) \mathrm{CH}\left(\mathrm{ONO}_{2}\right) \mathrm{CH}_{2} \mathrm{OH}$ & INDO2 \\
\hline
\end{tabular}

The near-unity quantum yield of nitrooxy ketones can be rationalized by mechanisms similar to that proposed for the hydroperoxy enals HPALDs (Peeters and Müller, 2010). Photon absorption by the carbonyl chromophore yielding the excited S1 state and fast intersystem crossing (ISC) to the triplet $\mathrm{T} 1$ state may be followed, via spin exchange, by avoided crossing of the $\mathrm{T} 1$ surface with the repulsive $\mathrm{T} 2$ surface of the $\mathrm{O}-\mathrm{NO}_{2}$ chromophore, resulting in fast dissociation of the weak (ca. $40 \mathrm{kcal} \mathrm{mol}^{-1}$ ) $\mathrm{O}-\mathrm{NO}_{2}$ bond. Alternatively, a chemical rearrangement of the excited $\mathrm{T} 1$ state may lead to either indirect dissociation to the same final products or to multistep decomposition yielding $\mathrm{NO}$, a carbonyl and an acyloxy radical. Another possible mechanism is internal conversion (IC) of the initially excited singlet state S1 to the ground state $\mathrm{S} 0$, followed by prompt dissociation of the weakest bond, i.e. $\mathrm{O}-\mathrm{NO}_{2}$, due to the high vibrational energy. Indeed, in the photodissociation dynamics of ketones, IC of S1 to S0 is expected to compete effectively with ISC of S1 to the triplet T1 state (Favero et al., 2013). Due to the competition with collisional stabilization, this latter mechanism can only be effective for molecules that are not too large, allowing dissociation on the S0 surface still faster than $10^{9} \mathrm{~s}^{-1}$.

In any case, a quantum yield not much below unity is likely also for other carbonyl nitrates, including the $\beta$-nitrooxy ketone and nitrooxy aldehydes of Table 1 , in particular the enal NC4CHO structurally very similar to HPALDs (replacing $\mathrm{ONO}_{2}$ by a hydroperoxy group). For simplicity, we will assume a value of unity in the calculations presented in the next section, and $\mathrm{O}-\mathrm{NO}_{2}$ breakup will be assumed to be the only photolysis channel considered. Typical photolysis rates of key carbonyl nitrates from isoprene implied by the above recommendations for cross sections and quantum yields are given in Table 3. 
Table 3. Sink rates of carbonyl nitrates due to photolysis $(J)$ and reaction with $\mathrm{OH}\left(k_{\mathrm{OH}} \cdot[\mathrm{OH}]\right)$, and overall lifetime $\tau=1 /\left(J+k_{\mathrm{OH}} \cdot\right.$ $[\mathrm{OH}]), k_{\mathrm{OH}}$ taken as the average of Neeb (2000) and MCMv3.2. $[\mathrm{OH}]=5 \times 10^{6}$ molec. $\mathrm{cm}^{-3}$. Photolysis rates calculated with TUV for $30^{\circ}$ solar zenith angle and $300 \mathrm{DU}$ ozone. Hydroxy group effects in MVKNO3, MACRNO3 and HMVKANO3 photolysis were neglected in this calculation.

\begin{tabular}{lccr}
\hline Compound & $\begin{array}{c}J \\
\left(\mathrm{~s}^{-1}\right)\end{array}$ & $\begin{array}{c}k_{\mathrm{OH}} \cdot[\mathrm{OH}] \\
\left(\mathrm{s}^{-1}\right)\end{array}$ & $\begin{array}{r}\tau \\
(\mathrm{h})\end{array}$ \\
\hline $\mathrm{NOA}$ & $3.5 \times 10^{-5}$ & $4 \times 10^{-6}$ & 7.1 \\
$\mathrm{MVKNO} 3$ & $5.6 \times 10^{-5}$ & $8 \times 10^{-6}$ & 4.3 \\
$\mathrm{HMVKANO} 3$ & $3.2 \times 10^{-5}$ & $1 \times 10^{-5}$ & 6.6 \\
\hline $\mathrm{NO}_{3} \mathrm{CH}_{2} \mathrm{CHO}$ & $1.5 \times 10^{-4}$ & $1.2 \times 10^{-5}$ & 1.7 \\
$\mathrm{MACRNO}$ & $3.5 \times 10^{-4}$ & $1.6 \times 10^{-5}$ & 0.76 \\
\hline $\mathrm{NC} 4 \mathrm{CHO}$ & $5.6 \times 10^{-4}$ & $2.1 \times 10^{-4}$ & 0.36
\end{tabular}

\section{Evaluation against isoprene oxidation experiment of Paulot et al. (2009)}

Thanks to the chemical ionization mass spectrometry (CIMS) technique, a wide range of products could be monitored in the isoprene oxidation experiment of Paulot et al. (2009), although interpretation is made difficult by the possible confusion between different isobaric compounds contributing to the same signal. With that limitation in mind, Paulot et al. (2009) analysed the different signals to constrain a large number of mechanistic parameters (branching ratios and kinetic rates) in a detailed, quasi-explicit chemical mechanism. To a large extent, those new constraints are adopted in the mechanism described in the next subsection. The photolysis of organic nitrates was, however, essentially neglected by Paulot et al. (2009), since the very low photorates of simple alkyl nitrates $\left(<10^{-6} \mathrm{~s}^{-1}\right.$ in the Caltech chamber) were adopted for carbonyl nitrates. Reaction with $\mathrm{OH}$ being the only other sink for those compounds, their rates adjusted by Paulot et al. (2009) on the basis of the CIMS signals were found to be substantially overestimated compared to both structure-activity-relationships (SARs) (e.g. Neeb, 2000) and, in the case of the nitrooxy ketones, recent laboratory measurements for very similar compounds (SuarezBertoa et al., 2012). A reevaluation of the respective roles of photolysis and $\mathrm{OH}$ oxidation of carbonyl nitrates is therefore clearly needed.

The experiment was conducted at high $\mathrm{NO}_{\mathrm{x}}$ using $\mathrm{H}_{2} \mathrm{O}_{2}$ photolysis as $\mathrm{OH}$ source, with $J\left(\mathrm{H}_{2} \mathrm{O}_{2}\right)=3.1 \times 10^{-6} \mathrm{~s}^{-1}$. The lamps are blacklights (GE350BL) irradiating above $300 \mathrm{~nm}$, with a maximum at $354 \mathrm{~nm}$ (Kroll et al., 2006; Cocker et al., 2001). Initial conditions are 500 ppbv NO, $94 \mathrm{ppbv}$ isoprene and $2.1 \mathrm{ppmv} \mathrm{H}_{2} \mathrm{O}_{2}$. Our chemical box model uses the Kinetic Preprocessor (KPP) package (Sandu et al., 2006) with its embedded Rosenbrock solver of order 4.

\subsection{General lines of isoprene mechanism}

The chemical degradation mechanism of isoprene at high $\mathrm{NO}$ is largely based on the MCMv3.2 (http://mcm.leeds.ac. $\mathrm{uk} / \mathrm{MCM} /$ ), with a number of updates. Inorganic reaction rates were revised based on the JPL recommendation (Sander et al., 2011).

Due to the high initial NO level and moderate temperatures (291.5-296.5 K) in the experiment of Paulot et al. (2009), the isomerization reactions proposed by Peeters et al. (2009) for $\mathrm{Z}-\delta$-hydroxyperoxy radicals from isoprene $+\mathrm{OH}$ and by Crounse et al. (2012) for $\beta$-hydroxyperoxy radicals from $\mathrm{MACR}+\mathrm{OH}$ were both too slow (of the order of $1 \mathrm{~s}^{-1}$ or less) to compete with their reaction with $\mathrm{NO}$, and are therefore neglected here. The only non-negligible unimolecular reactions of the isoprenyl peroxy radicals are their $\mathrm{O}_{2}$ loss reactions, with rates of the order of $10 \mathrm{~s}^{-1}$ for the least stable radical (at $292 \mathrm{~K}$, the temperature prevailing in the isoprene consumption stage which lasted $20 \mathrm{~min}$ ) (Peeters and Müller, 2010). Because the Z- $\delta$-hydroxy peroxys from isoprene decompose faster than their $\beta$-hydroxy counterparts, the net effect of the $\mathrm{O}_{2}$ elimination and re-addition reactions is to increase the yield of $\beta$-hydroxy peroxy products such as MVK, MACR and the $\beta$-hydroxy-nitrates, at the expense of the $\delta$-hydroxyperoxy products, including the $\delta$-hydroxynitrates. Although this effect is estimated to be substantial in atmospheric conditions, as it reduces the $\delta$-hydroxyperoxy product yield by an order of magnitude (Peeters and Müller, 2010), it is very small at the high NO levels of Paulot et al. (2009) and is therefore not considered here.

We adopt the MCMv3.2 branching ratios for the formation of the different hydroxyperoxy radicals from isoprene $+\mathrm{OH}$, which include the $\beta$-hydroxyperoxys ISOPBO2 and ISOPDO 2 and the $\delta$-hydroxyperoxys ISOPAO2 and ISOPCO2 (Table 2). Note that $\mathrm{OH}$ addition to the central carbons of isoprene is ignored, as it represents only about $7 \%$ of the total (Park et al., 2004). Whereas the overall nitrate yield in the reaction of first-generation isoprene peroxys with $\mathrm{NO}$ is relatively well constrained $(8 \pm 3 \%)$ by experimental data (Atkinson et al., 2006), the yields of individual nitrates are much more uncertain (Orlando and Tyndall, 2012). We adopt here the yields derived by Paulot et al. (2009): $6.7 \%$ for the $\beta$-hydroxyperoxys and $24 \%$ for the $\delta$-hydroxyperoxys, slightly higher than in a previous experimental study (Giacopelli et al., 2005). Note that those much higher yields for $\delta$ - compared to $\beta$-hydroxyperoxys appear to be at odds with previous findings showing that 1,4-substitutions tend to reduce the nitrate yield, as discussed by Orlando and Tyndall (2012). An alternative choice (8\%) for the yield of $\delta$-hydroxy-nitrates will be therefore also tested with the model. 


\subsection{Pathways to carbonyl nitrates}

Carbonyl nitrates are formed from both the further degradation of the first-generation hydroxy-nitrates (see below) and the oxidation of the major products MVK and MACR by $\mathrm{OH}$ and $\mathrm{O}_{3}$. MACRNO3 is, for example, formed from $\mathrm{OH}$ addition to the external carbon of the double bond in MACR, followed by $\mathrm{O}_{2}$ addition and reaction with NO. MVKNO3 (HMVKANO3) is formed from the major (minor) $\mathrm{OH}$ addition to MVK, namely to the external (internal) carbon of the double bond, followed by $\mathrm{O}_{2}$ addition and $\mathrm{NO}$ reaction. We adopt here the nitrate yields in those NO reactions estimated by Paulot et al. (2009): $15 \%$ for MACRNO3 and $11 \%$ for MVKNO3+HMVKANO3, consistent with a previous laboratory study (Chuong and Stevens, 2004). The branching ratio for addition to the terminal carbon of MVK is $85 \%$, based on the SAR of Peeters et al. (2007), as validated for similar enone compounds by Orlando et al. (1999) and Orlando and Tyndall (2002).

The first-generation hydroxy-nitrates from isoprene can undergo reaction with $\mathrm{OH}$ and $\mathrm{O}_{3}$, whereas photolysis is very slow (ca. $10^{-6} \mathrm{~s}^{-1}$ or less). According to MCMv3.2, the ozonolysis of each major hydroxynitrate (ISOPANO3, ISOPBNO3, ISOPCNO3 and ISOPDNO3) generates a different carbonyl nitrate $\left(\mathrm{NO}_{3} \mathrm{CH}_{2} \mathrm{CHO}\right.$, MACRNO3, NOA and MVKNO3, respectively) at overall yields of 0.55-0.6. Since, as will be shown in Sect. 4.3, the reaction with ozone plays only a minor role in the experimental conditions of Paulot et al. (2009), the following discussion focuses on the $\mathrm{OH}$-degradation mechanism.

$\mathrm{OH}$ addition to ISOPBNO3 and ISOPDNO3 proceeds primarily by terminal addition ( $85 \%$ ) (Peeters et al., 2007), followed by $\mathrm{O}_{2}$ addition to the internal $\mathrm{C}$. The NO reaction of the resulting peroxy radicals (INB1O2 from ISOPBNO3 and INDO2 from ISOPDNO3; see Table 2) generates oxy radicals (INB1O and INDO), each decomposing following two possible pathways:

$\mathrm{INB} 1 \mathrm{O} \rightarrow \mathrm{ACETOL}+\mathrm{HOCH}_{2} \mathrm{CHO}+\mathrm{NO}_{2}$,

$\mathrm{INB} 1 \mathrm{O} \rightarrow \mathrm{MACRNO} 3+\mathrm{HCHO}$,

and

$\mathrm{INDO} \rightarrow \mathrm{ACETOL}+\mathrm{HOCH}_{2} \mathrm{CHO}+\mathrm{NO}_{2}$,

$\mathrm{INDO} \rightarrow \mathrm{MVKNO} 3+\mathrm{HCHO}$.

We adopt the branching ratios proposed by Paulot et al. (2009) consistent with their experimental results: $60 \%$ for both Reaction (R1a) and Reaction (R1b). Note that in MCMv3.2, path Reaction (R2a) is ignored and Reaction (R2b) is largely dominant $(\sim 90 \%)$. For both oxy radicals, the difference between the SAR-predicted barrier heights (Vereecken and Peeters, 2009) for the two possible channels is small $\left(1-2 \mathrm{kcal} \mathrm{mol}^{-1}\right)$ implying that $\mathrm{H}$-bonding effects - not accounted for in the SAR but possibly exceeding $2 \mathrm{kcal} \mathrm{mol}^{-1}$ - could decide the real branching fractions.

Upon $\mathrm{OH} / \mathrm{O}_{2}$ addition to ISOPANO3, reaction with $\mathrm{NO}$ of the resulting peroxy radical INAO2 (Table 2) forms an oxy radical decomposing to hydroxy-acetone and (upon $\mathrm{O}_{2}$ addition) an $\alpha$-hydroxyperoxy radical $\mathrm{HOCH}\left(\mathrm{O}_{2}\right) \mathrm{CH}_{2}\left(\mathrm{ONO}_{2}\right)$ expected to readily eliminate $\mathrm{HO}_{2}$ and thus form ethanal nitrate. An additional decomposition pathway (to $\mathrm{HCHO}+\mathrm{HCOOH}+\mathrm{NO}_{3}$ ), representing $70 \%$ of the total, was invoked by Paulot et al. (2009) in order to reduce the yield of ethanal nitrate and match its measured concentrations in their experiment. This unusually involved pathway must be invoked only under the assumption of a high nitrate yield $(0.24)$ in the reaction of $\delta$-peroxynitrates with NO. It is therefore not considered in model runs assuming a low nitrate yield (8\%).

Finally, the reaction with $\mathrm{NO}$ of the peroxy radical (INCO2) formed upon $\mathrm{OH} / \mathrm{O}_{2}$ addition to ISOPCNO3 produces an oxy radical decomposing to NOA and glycolaldehyde. The alternative pathway proposed by Paulot et al. (2009), i.e. decomposition to dihydroxybutanone $+\mathrm{HCHO}+\mathrm{NO}_{2}$, is predicted to face a ca. $8 \mathrm{kcal} \mathrm{mol}^{-1}$ higher barrier (Vereecken and Peeters, 2009) and is therefore neglected.

\subsection{Constraining the $\mathrm{OH}$ - and $\mathrm{O}_{3}$ reaction rates of the $\beta$-hydroxy-nitrates from isoprene}

Paulot et al. (2009) inferred a low $\mathrm{OH}$-addition rate constant for the $\beta$-hydroxy-nitrates, $1.3 \times 10^{-11} \mathrm{~cm}^{3}$ molec. ${ }^{-1} \mathrm{~s}^{-1}$, found necessary to match the evolution of the CIMS signal of the isoprene hydroxy-nitrates. It is unclear why this rate is so different from the $\mathrm{OH}$-addition rate to the $\delta$ hydroxy-nitrates, $9.5 \times 10^{-11}$ in Paulot et al. (2009) and $6.9 \times 10^{-11} \mathrm{~cm}^{3}$ molec. $^{-1} \mathrm{~s}^{-1}$ in MCMv3.2. We adopt the MCMv3.2 value for the $\delta$-hydroxy-nitrates; the precise value was found to have little influence on the modelling results.

Although ozonolysis is relatively unimportant for the $\delta$ hydroxy-nitrates due to their high reactivity towards $\mathrm{OH}$ (Paulot et al., 2009), it might play a significant yet uncertain role for the $\beta$-hydroxy-nitrates. Rates of the order of $10^{-17} \mathrm{~cm}^{3}$ molec. $^{-1} \mathrm{~s}^{-1}$ were assumed by Giacopelli et al. (2005) and Paulot et al. (2009) based on previous measurements for terminal alkenes. However, a much higher ozonolysis rate was recently determined in the laboratory by Lockwood et al. (2010) for the 1,2-hydroxynitrate ISOPBNO3 $\left(10.6 \times 10^{-17} \mathrm{~cm}^{3}\right.$ molec. $\left.{ }^{-1} \mathrm{~s}^{-1}\right)$, about twice higher than the measured rate for the 1,4-hydroxynitrate ISOPCNO3 $\left(5.3 \times 10^{-17} \mathrm{~cm}^{3}\right.$ molec. $\left.^{-1} \mathrm{~s}^{-1}\right)$. Those values were adopted in MCMv3.2 and in recent global model studies (Xie et al., 2013; Mao et al., 2013) for all isoprene $\beta$ - and $\delta$-hydroxynitrates, respectively. 

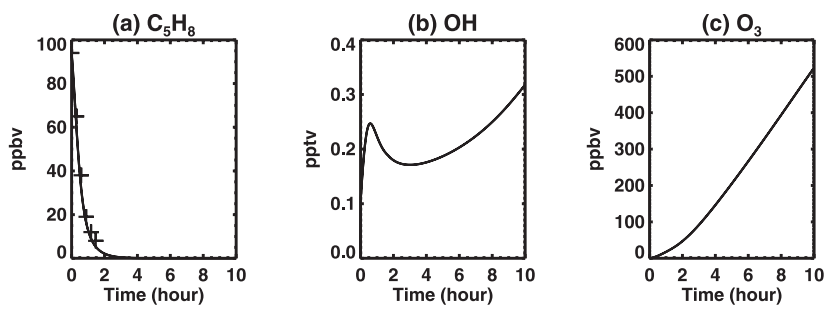

Fig. 3. Calculated mixing ratios of (a) isoprene, (b) $\mathrm{OH}$ and (c) ozone in the experiment of Paulot et al. (2009). The reported measurements of isoprene are shown as black crosses.

Figure 3 shows the calculated time profiles of isoprene, $\mathrm{OH}$ radical and ozone in the isoprene oxidation experiment. Those results are very similar to the modelling results of Paulot et al. (2009). Isoprene is entirely consumed within the first $2 \mathrm{~h}$. Whereas $\mathrm{OH}$ concentrations show only moderate variations, ranging between 0.2 and 0.3 pptv (or about 5 and $7 \times 10^{6}$ molec. $\mathrm{cm}^{-3}$ ), ozone is predicted to increase continuously from near zero to about $500 \mathrm{ppbv}$ after $10 \mathrm{~h}$. Owing to their short chemical lifetime $(<1 \mathrm{~h})$, the $\delta$-hydroxynitrates are expected to be consumed within the first $4 \mathrm{~h}$. At later times, the temporal profile of the isoprene hydroxynitrates (Fig. 4) is controlled solely by the reactions of the $\beta$ hydroxy-nitrates with $\mathrm{OH}$ and $\mathrm{O}_{3}$. In the first hours, however, the profile is also dependent on the respective yields of $\beta$-vs. $\delta$-hydroxy-nitrates. For this reason, we show model results obtained using either a high $\left(Y_{\delta}=0.24\right)$ or low $\left(Y_{\delta}=0.08\right)$ value for the nitrate yield in the reaction of $\delta$-hydroxyperoxys with NO.

In the first case (left panel of Fig. 4), the sensitivity calculations are fully consistent with the conclusions of Paulot et al. (2009) - the best results are obtained when using low values for both rate coefficients of the $\beta$-hydroxy-nitrates: $k_{\mathrm{OH}}=1.3 \times 10^{-11}$ and $k_{\mathrm{O}_{3}}=1 \times 10^{-17} \mathrm{~cm}^{3}$ molec. $^{-1} \mathrm{~s}^{-1}$. Adopting the very high ozonolysis rate by Lockwood et al. (2010) (VH run) leads to an almost complete disappearance of the hydroxy-nitrates after only $4 \mathrm{~h}$ due to the short chemical lifetime $(<30 \mathrm{~min}$ after $4 \mathrm{~h}$ of experiment) implied by the high reaction rate. The chemical sink after $6 \mathrm{~h}$ is overestimated by more than a factor of 5 in this simulation. Even a moderately high ozonolysis rate of $3 \times 10^{-17} \mathrm{~cm}^{3}$ molec. $^{-1} \mathrm{~s}^{-1}$ is clearly incompatible with the data. As can be seen in Fig. 4, these conclusions are independent on the choice of $Y_{\delta}$ and should therefore be considered as robust.

When a low yield of $\delta$-hydroxy-nitrates is adopted, the best results are obtained when using a higher $\mathrm{OH}$-reaction rate for the $\beta$-hydroxy-nitrates $\left(2.2 \times 10^{-11} \mathrm{~cm}^{3}\right.$ molec. $\left.^{-1} \mathrm{~s}^{-1}\right)$, which compensates for the lower share of the short-lived $\delta$-hydroxy-nitrates to the CIMS signal in the first hours of the experiment. As a result of the higher $k_{\mathrm{OH}}$, the profile shape at later times requires a further lowering of the ozonolysis rate, explaining the better agreement ob- tained in the simulation using the lowest value for $k_{\mathrm{O} 3}$ $\left(0.5 \times 10^{-17} \mathrm{~cm}^{3}\right.$ molec. $\left.{ }^{-1} \mathrm{~s}^{-1}\right)$.

\subsection{Sinks of carbonyl nitrates: photolysis vs. $\mathrm{OH}$ reaction}

The (saturated) carbonyl nitrates from isoprene can undergo photolysis and $\mathrm{H}$ abstraction by $\mathrm{OH}$ radicals. Photolysis is assumed to eliminate $\mathrm{NO}_{2}$. Merging the initial photolysis reaction with the fast subsequent unimolecular reaction of the oxy co-product (and possibly reaction with $\mathrm{O}_{2}$ ) yields

$\mathrm{NOA}+h v \rightarrow \mathrm{NO}_{2}+\mathrm{CH}_{3} \mathrm{CO}_{3}+\mathrm{HCHO}$

$\mathrm{MVKNO} 3+h v \rightarrow \mathrm{NO}_{2}+\mathrm{CH}_{3} \mathrm{CO}_{3}+\mathrm{HOCH}_{2} \mathrm{CHO}$

$\mathrm{HMVKANO} 3+h v \rightarrow \mathrm{NO}_{2}+\mathrm{MGLY}+\mathrm{HCHO}+\mathrm{HO}_{2}$

$\mathrm{NO}_{3} \mathrm{CH}_{2} \mathrm{CHO}+h v \rightarrow \mathrm{NO}_{2}+\mathrm{HCHO}+\mathrm{CO}+\mathrm{HO}_{2}$

$\mathrm{MACRNO} 3+h v \rightarrow \mathrm{NO}_{2}+\mathrm{ACETOL}+\mathrm{CO}+\mathrm{HO}_{2}$,

where MGLY denotes methylglyoxal. The photolysis reactions of the other carbonyl nitrates generated in the oxidation of isoprene are given in the Supplement. The $\mathrm{OH}-$ oxidation mechanism is obtained from MCMv3.2. The OHreaction rates are taken either from the SAR of Neeb (2000) or from the MCMv3.2, itself based on previous SARs. In both cases, the rates are substantially lower than the values determined by Paulot et al. (2009) for $\mathrm{NO}_{3} \mathrm{CH}_{2} \mathrm{CHO}$, MACRNO3 and MVKNO3 based on the CIMS profiles, very likely due the underestimation of photolysis in their analysis. The analysis by Neeb (2000) of kinetic measurements for a large number of alkyl nitrates indicates that the presence of the $\mathrm{ONO}_{2}$ group reduces drastically the $\mathrm{H}$-abstraction rate on both $\alpha$ - and $\beta$-carbons. The OH-reaction rates of three nitrooxy ketones, namely $\alpha$-nitrooxy acetone, 3 -nitrooxy2-butanone and 3-methyl-3-nitrooxy-2-butanone, were measured recently by Suarez-Bertoa et al. (2012), with values, in units of $10^{-12} \mathrm{~cm}^{3}$ molec. ${ }^{-1} \mathrm{~s}^{-1}$, of $0.67 \pm 0.25,1.06 \pm 0.41$ and $0.26 \pm 0.09$, respectively. These values fall between the estimates by Neeb (2000) (0.58, 0.68 and 0.24 , respectively) and the MCMv3.2 (1.0, 1.2 and 0.34). These SAR estimates always lie within the experimental error bars, except in the case of MCMv3.2 for NOA.

The difference between MCMv3.2 and Neeb (2000) is large in the case of nitrooxy aldehydes, e.g. for ethanal nitrate $\mathrm{NO}_{3} \mathrm{CH}_{2} \mathrm{CHO}: k_{\mathrm{OH}}=1.2 \times 10^{-12}$ (Neeb) vs. $3.4 \times 10^{-12} \mathrm{~cm}^{3}$ molec. $^{-1} \mathrm{~s}^{-1}$ (MCM). Nevertheless, the impact of this difference is relatively small on the modelled temporal profile of $\mathrm{NO}_{3} \mathrm{CH}_{2} \mathrm{CHO}$, as seen in Fig.5. Whichever SAR estimate is used for the $\mathrm{OH}$ reaction rate, the low photorate estimated by MCM 

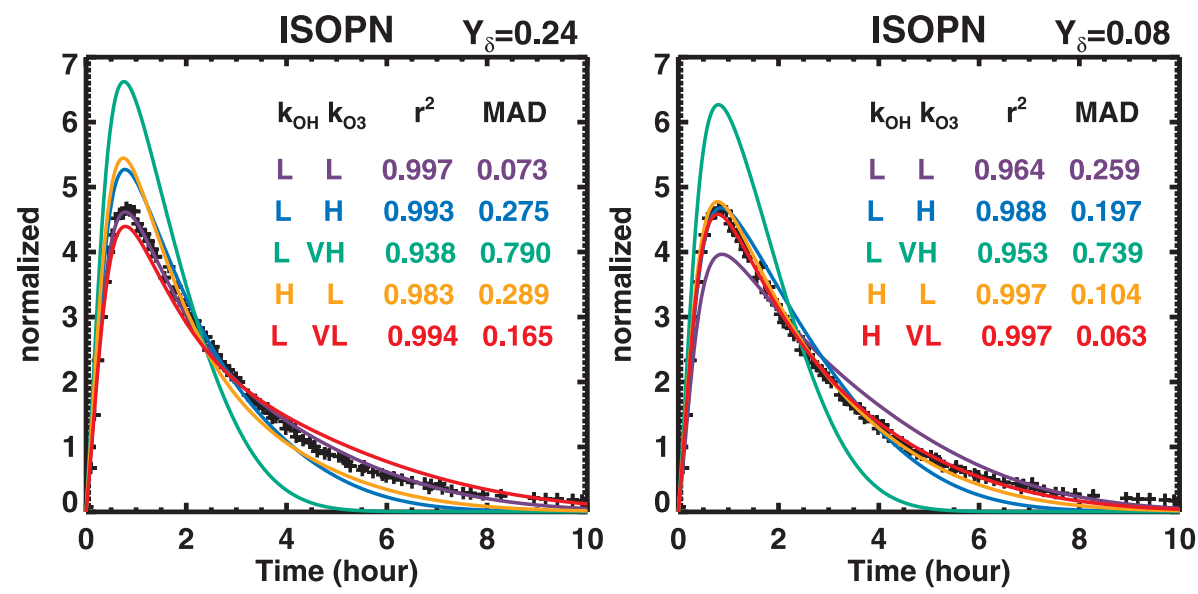

Fig. 4. Calculated mixing ratios of the normalized sum of first-generation isoprene nitrates weighted by their calibration factors in the experiment of Paulot et al. (2009). The reported measurements are shown as black crosses. The assumed nitrate yield in the reaction of $\delta$-hydroxyperoxy radicals from isoprene is either 0.24 (left panel) or 0.08 (right). The model runs differ in the assumed reaction rates of isoprene $\beta$-hydroxy-nitrates with $\mathrm{OH}$ and $\mathrm{O}_{3}$. The values for $k_{\mathrm{OH}}$ are $1.3 \times 10^{-11}(\mathrm{~L})$ and $2.2 \times 10^{-11}(\mathrm{H}) \mathrm{cm}^{3} \mathrm{molec}^{-1} \mathrm{~s}^{-1}$. The values for $k_{\mathrm{O}_{3}}$ are $0.5 \times 10^{-17}(\mathrm{VL}), 10^{-17}(\mathrm{~L}), 3 \times 10^{-17}(\mathrm{H})$ and $10.6 \times 10^{-17}(\mathrm{VH}) \mathrm{cm}^{3}$ molec. ${ }^{-1} \mathrm{~s}^{-1}$. The (squared) Pearson correlation coefficients and mean absolute deviations (MAD) are also indicated.

$\left(J_{\mathrm{MCM}}=1.7 \times 10^{-6} \mathrm{~s}^{-1}\right)$ leads to a strong underestimation of the decay of $\mathrm{NO}_{3} \mathrm{CH}_{2} \mathrm{CHO}$ after the concentration peak, i.e. at times $t>2-3 \mathrm{~h}$. In contrast, the high photolysis rate $\left(J_{\text {fast }}=4.4 \times 10^{-5} \mathrm{~s}^{-1}\right)$ calculated using enhanced absorption cross sections (Sect. 2) and a unit quantum yield leads to a far better agreement with the observed temporal profile. More precisely, a near-perfect fit at $t>5 \mathrm{~h}$ is obtained when adopting either $k_{\mathrm{OH}}$ from Neeb (2000) and $J=J_{\text {fast }}$ or $k_{\mathrm{OH}}$ from MCMv3.2 and $J=0.75 \cdot J_{\text {fast }}$ (not shown in the figure). The measurements therefore validate both the strongly enhanced cross sections (Sect. 2) and the assumption of a near-unit quantum yield (Sect. 3) for ethanal nitrate.

The choice of the OH-reaction SAR (Neeb or MCM) has very little influence on the temporal profile shape of the methyl vinyl ketone- and methacrolein nitrates (MVKNO3+HMVKANO3+MACRNO3), as seen in Fig. 6. As for ethanal nitrate, the simulations assuming a fast photolysis of carbonyl nitrates provide a better match with the observed temporal profile. The model results appear to be further improved by the use of a higher OH-reaction rate of $\beta$-hydroxynitrates (Fig. 6b), which was found consistent with the hypothesis of a low yield of $\delta$-hydroxy-nitrates (see Fig. 4). Reasons for the remaining discrepancy between the model and the CIMS measurements might be multiple, including, for example, still-underestimated photolysis rates or an underestimated production rate of the short-lived MACRNO3 compared to the comparatively longer-lived MVKNO3 and HMVKANO3. For example, an excellent agreement with the data $\left(r^{2}=0.99\right)$ can be achieved by doubling the photolysis rates of all three compounds.

Higher photorates for MVKNO3 and MACRNO3 might be explained by the effect of their hydroxy group in beta posi-

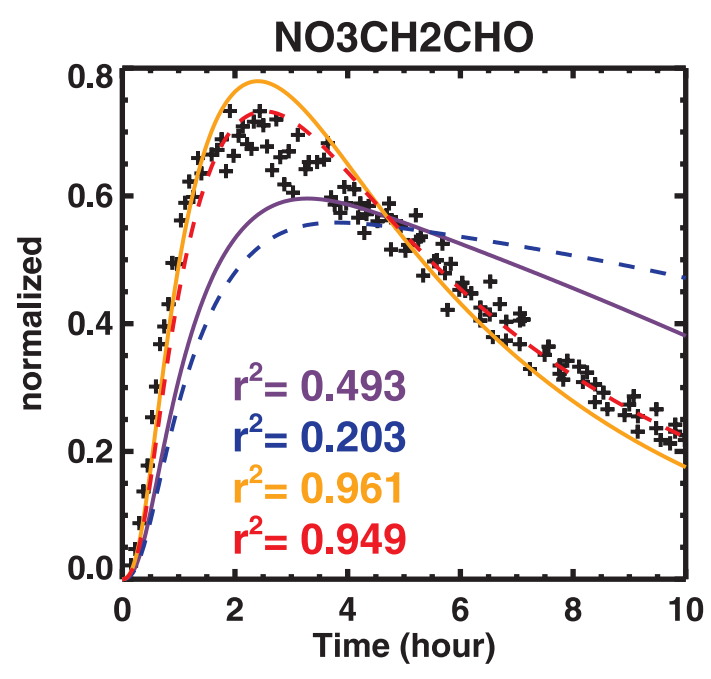

Fig. 5. Calculated mixing ratios of ethanal nitrate in the experiment of Paulot et al. (2009). The reported measurements are shown as black crosses. The model runs differ in the $\mathrm{OH}-$ reaction and photolysis rates. The $\mathrm{OH}-$ reaction rates are obtained either from the MCMv3.2 (full lines) or from Neeb (2000) (dashed lines). Indigo and blue curves: MCM photolysis; orange and red: fast photolysis as described in this article.

tion, as shown by the higher cross sections of the $\beta$-hydroxy ketone $\mathrm{CH}_{3} \mathrm{C}(\mathrm{O}) \mathrm{CH}_{2} \mathrm{CH}_{2} \mathrm{OH}$ (Messaadia et al., 2012) compared to methyl ethyl ketone (MEK) (Atkinson et al., 2006) above $320 \mathrm{~nm}$. Although measurement uncertainties might be significant at those wavelengths, the observed strong enhancement (exceeding a factor of 5 above $330 \mathrm{~nm}$ ) might be explained by (i) a red shift in the cross sections due to a lowering of the energy difference between the ground state S0 
(a)

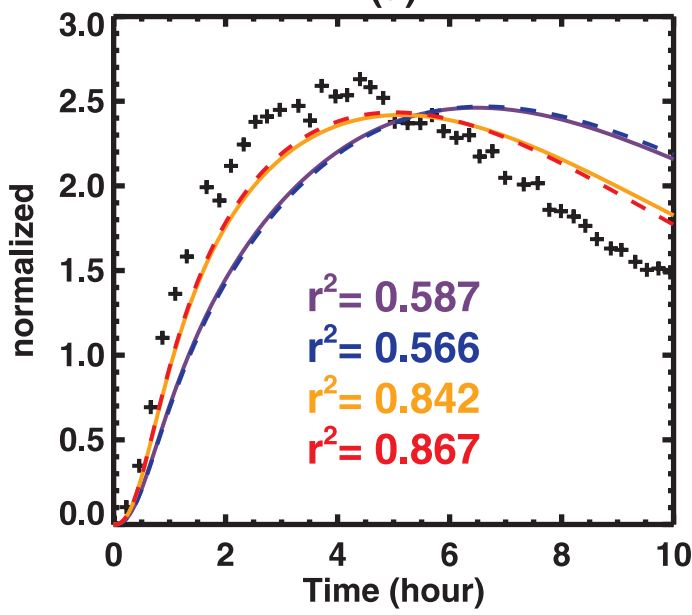

(b)

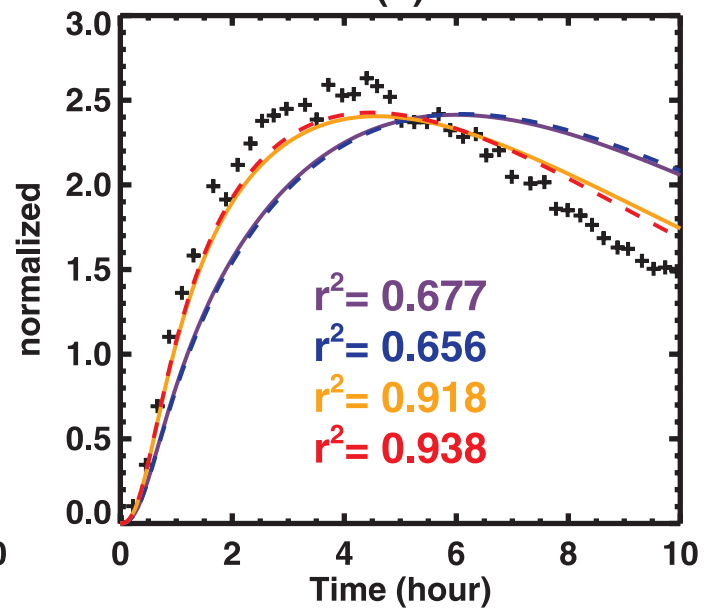

Fig. 6. Calculated mixing ratios of the normalized sum of MVKNO3 and isomers (HMVKANO3 and MACRNO3) in the experiment of Paulot et al. (2009). The reported measurements are shown as black crosses. The assumed OH-reaction rate of the isoprene $\beta$-hydroxy-nitrates is either (a) $1.3 \times 10^{-11}$ (left) or (b) $2.2 \times 10^{-11} \mathrm{~cm}^{3}$ molec. ${ }^{-1} \mathrm{~s}^{-1}$ (right). The model runs further differ in the OH-reaction and photolysis rates of the carbonyl nitrates. Indigo and blue curves: MCM photolysis; orange and red: fast photolysis as described in this article. The $\mathrm{OH}$-reaction rates are obtained either from the MCMv3.2 (full lines) or from Neeb (2000) (dashed lines). The (squared) Pearson correlation coefficients are also indicated.

and the excited state $\mathrm{S} 1$, resulting from a stronger $\mathrm{H}$ bond in $\mathrm{S} 1$ compared to $\mathrm{S} 0$ between the carbonyl $\mathrm{O}$ and the hydroxy H, and (ii) the so-called hot bands, i.e. excitations of vibrationally excited levels of S0, expected near the $0 \mathrm{~K}$ bandlimit (ca. $335 \mathrm{~nm}$ ). The significance of the latter effect is made clear by the case of 3-hydroxy 3-methyl 2-butanone: its cross sections were found by Messaadia et al. (2012) to be almost an order of magnitude higher than those of 3-hydroxy 2butanone around $335 \mathrm{~nm}$, indicating that the increased number of low-frequency vibration modes due to the additional $\mathrm{CH}_{3}$ group causes a substantially increased absorption near the $0 \mathrm{~K}$ bandlimit.

In contrast, the presence of a hydroxy group in alpha position in HMVKANO3 is expected to decrease its cross sections based on the measured cross sections of hydroxyacetone (Atkinson et al., 2006) and 3-hydroxy 2-butanone (Messaadia et al., 2012). Nonetheless, since this compound represents only a minor $(<10 \%)$ fraction of the sum MVKNO3+HMVKANO3+MACRNO3, the overall impact of the hydroxy group on the photolysis rates is very likely a significant enhancement, consistent with the above model results.

\section{Atmospheric implications}

Photolysis is found to be, by far, the dominant sink of isoprene-derived carbonyl nitrates in relevant atmospheric conditions, as seen in Table 3. Adopting a concentration of $\mathrm{OH}\left(5 \times 10^{6}\right.$ molec. $\left.\mathrm{cm}^{-3}\right)$ typically measured during daytime over Amazonia (Lelieveld et al., 2008) and the eastern
United States in summer (Ren et al., 2008), the clear-sky photorates are estimated to be between $\sim 3$ and 20 times higher than the sink due to reaction with $\mathrm{OH}$, even when neglecting hydroxy group effects. This has important consequences regarding the role of isoprene nitrate formation on the budget of $\mathrm{NO}_{\mathrm{x}}$, because whereas photolysis is expected to release $\mathrm{NO}_{2}$, the nitrate group is very often retained in the reaction of carbonyl nitrates with $\mathrm{OH}$, leading to a variety of compounds including aldehydes, peroxyacyl nitrates and hydroperoxides, all bearing the nitrate group. Needless to say, the subsequent degradation of those compounds is complex and uncertain, and therefore difficult to represent in large-scale models. Photolysis, on the other hand, is more effective in depleting the total organic nitrate pool, and it leads to a generally much simpler chemistry, as seen in the cases of the isoprene nitrates considered in Sect. 4.4. The dominance of photolysis as a sink for carbonyl nitrates, and particularly for the $\alpha$-nitrooxy aldehydes (Table 3), should therefore facilitate the elaboration of reduced chemical mechanisms for use in large-scale models.

The estimated lifetimes of the key secondary isoprene nitrates (Table 3) can be compared to the lifetime of the firstgeneration $\beta$-hydroxy-nitrates from isoprene, between 2.4 and $3.8 \mathrm{~h}$ (assuming $35 \mathrm{ppbv} \mathrm{O}_{3}$ and $5 \times 10^{6}$ molec. $\mathrm{cm}^{-3}$ $\mathrm{OH}$, and using $k_{\mathrm{OH}}$ and $k_{\mathrm{O} 3}$ determined in Sect. 4.3). The $\delta$-hydroxy-nitrates are comparatively much shorter lived $(0.5 \mathrm{~h})$ but are expected to be unimportant in atmospheric conditions because their yields are predicted to be reduced by about one order of magnitude due to the fast interconversion of isoprene hydroxyperoxys (Peeters and Müller, 2010). Note that this yield reduction is consistent 
with the absence of atmospheric measurements for the $\mathrm{C}_{5}$-hydroxyaldehydes (produced alongside the $\delta$-hydroxynitrates) known to be formed in high yields in the oxidation of isoprene by $\mathrm{OH}$ at very high $\mathrm{NO}$ (Atkinson et al., 2006). From these considerations, and since nitrooxy acetone is essentially not formed from the $\beta$-hydroxy pathways, the photochemical lifetime of the major secondary nitrates from isoprene $+\mathrm{OH}$ in atmospheric conditions (i.e. mostly MVKNO3 and MACRNO3) is estimated to be relatively similar, or even possibly lower, than the lifetime of the first-generation $(\beta$-)hydroxy-nitrates. This is broadly consistent with the CIMS measurements of primary and secondary isoprene nitrates during the BEARPEX 2009 campaign in California, which indicate about twice higher concentrations of first-generation hydroxy-nitrates compared to second-generation nitrates (Beaver et al., 2012). In contrast, a Lagrangian model study (Perez et al., 2009) using an updated version of MCMv3.1 predicted that second-generation nitrates should be about 6 times more abundant than the firstgeneration hydroxy-nitrates, due to the assumed high reactivity of the latter and neglected photolysis of the former.

\section{Conclusions}

Interactions between functional groups were shown to play a crucial role in the photolysis of carbonyl nitrates. The nitrate group appears to (1) enhance photon absorption by the carbonyl chromophore and (2) facilitate dissociation upon photon absorption, to a point that the quantum yield is close to unity, with $\mathrm{O}-\mathrm{NO}_{2}$ dissociation as the likely major (or only) photolysis channel. We tentatively quantified these effects using existing laboratory data for the cross sections (Barnes et al., 1993) and photolysis rates (Suarez-Bertoa et al., 2012) of specific $\alpha$-nitrooxy ketones. In absence of direct measurements of photolysis parameters for nitrooxy aldehydes, our recommended photorate estimation has a potentially large uncertainty for those compounds. Fortunately, an unexpected validation is provided in the case of ethanal nitrate, the simplest nitrooxy aldehyde, by its CIMS temporal profile in the isoprene oxidation experiment of Paulot et al. (2009), as it implies a strong sink besides $\mathrm{OH}$ reaction, consistent with our assumptions regarding the photolysis parameters. Photolysis is also shown to be a major sink for the key secondary nitrates MVKNO3 and isomers. A further enhancement of their cross sections due to their hydroxy group (in beta position in MVKNO3 and MACRNO3) is also supported by the model comparisons.

Given the noted importance of carbonyl nitrate photolysis for the budget of $\mathrm{NO}_{\mathrm{x}}$, and therefore ozone in the troposphere, the need for additional laboratory data should be acknowledged. For example, absorption cross-section measurements for (1) $\alpha$-nitrooxy aldehydes and (2) $\beta$-nitrooxy carbonyls would be especially helpful in order to validate and refine the above conclusions. Also, cross-section enhancement effects might exist for other bifunctional carbonyls, including hydro-peroxides and peracids, and should be explored. A reduced chemical mechanism incorporating those effects should be elaborated and implemented in atmospheric chemistry models in order to evaluate the impact of mechanistic assumptions and rate estimations against field campaigns.

\section{Supplementary material related to this article is available online at http://www.atmos-chem-phys.net/14/ 2497/2014/acp-14-2497-2014-supplement.pdf.}

Acknowledgements. This research was supported by the PRODEX project A3C (2011-2013) and by the project BIOSOA (SD/CS/05A, 2011-2014) funded by the Belgian Science Policy Office.

Edited by: P. O. Wennberg

\section{References}

Atkinson, R., Baulch, D. L., Cox, R. A., Crowley, J. N., Hampson, R. F., Hynes, R. G., Jenkin, M. E., Rossi, M. J., Troe, J., and IUPAC Subcommittee: Evaluated kinetic and photochemical data for atmospheric chemistry: Volume II - gas phase reactions of organic species, Atmos. Chem. Phys., 6, 3625-4055, doi:10.5194/acp-6-3625-2006, 2006.

Baeza-Romero, M. T., Blitz, M. A., Heard, D. E., Pilling, M. J., Price, B., Seakins, P. W., and Wang, L.: Photolysis of methylethyl, diethyl and methylvinyl ketones and their role in the atmospheric $\mathrm{HO}_{\mathrm{x}}$ budget, Faraday Discuss., 130, 73-88, 2005.

Barnes, I., Becker, K. H., and Zhu, T.: Near UV absorption spectra and photolysis products of difunctional organic nitrates: Possible importance as $\mathrm{NO}_{\mathrm{x}}$ reservoirs, J. Atmos. Chem. 17, 353-373, 1993.

Beaver, M. R., Clair, J. M. St., Paulot, F., Spencer, K. M., Crounse, J. D., LaFranchi, B. W., Min, K. E., Pusede, S. E., Wooldridge, P. J., Schade, G. W., Park, C., Cohen, R. C., and Wennberg, P. O.: Importance of biogenic precursors to the budget of organic nitrates: observations of multifunctional organic nitrates by CIMS and TD-LIF during BEARPEX 2009, Atmos. Chem. Phys., 12, 5773-5785, doi:10.5194/acp-12-5773-2012, 2012.

Blitz, M. A., Heard, D. E., and Pilling, M. J.: Pressure and temperature-dependent quantum yields for the photodissociation of acetone between 279 and $327.5 \mathrm{~nm}$, Geophys. Res. Lett., 31, L06111, doi:10.1029/2003GL018793, 2004.

Capouet, M., Müller, J.-F., Ceulemans, K., Compernolle, S., Vereecken, L., and Peeters, J.: Modeling aerosol formation in alpha-pinene oxidation experiments, J. Geophys. Res., 113, D02308, doi:10.1029/2007JD008995, 2008.

Chuong, B. and Stevens, P. S.: Measurements of the kinetics of the $\mathrm{OH}$-initiated oxidation of methyl vinyl ketone and methacrolein, Int. J. Chem. Kinet., 36, 12-25, 2004.

Cocker, D. R., Flagan, R. C., and Seinfeld, J. H.: State-of-the-art chamber facility for studying atmospheric aerosol chemistry, Environ. Sci. Technol., 35, 2594-2601, 2001. 
Compernolle, S., Ceulemans, K., and Müller, J.-F.: EVAPORATION: a new vapour pressure estimation methodfor organic molecules including non-additivity and intramolecular interactions, Atmos. Chem. Phys., 11, 9431-9450, doi:10.5194/acp-119431-2011, 2011.

Crounse, J. D., Paulot, F., Kjaergaard, H. G., and Wennberg, P. O.: Peroxy radical isomerisation in the oxidation of isoprene, Phys. Chem. Chem. Phys., 13, 13607-13613, 2011.

Crounse, J. D., Knap, H. C., Ørnsø, K. B., Jørgensen, S., Paulot, F., Kjaergaard, H. G., and Wennberg, P. O.: Atmospheric fate of methacrolein. 1. Peroxy radical isomerization following addition of $\mathrm{OH}$ and $\mathrm{O}_{2}$, J. Phys. Chem., 116, 5756-5762, 2012.

Favero, L., Granucci, G., and Persico, M.: Dynamics of acetone photodissociation: a surface hopping study, Phys. Chem. Chem. Phys., 15, 20651-20661, 2013.

Giacopelli, P., Ford, K., Espada, C., and Shepson, P. B.: Comparison of the measured and simulated isoprene nitrate distributions above a forest canopy, J. Geophys. Res., 110, D01304, doi:10.1029/2004JD005123, 2005.

Kroll, J. H., Ng, N. L., Murphy, S. M., Flagan, R. C., and Seinfeld, J. H.: Secondary organic aerosol formation from isoprene photooxidation, Environ. Sci. Technol., 40, 1869-1877, 2006.

Kwan, A. J., Chan, A. W. H., Ng, N. L., Kjaergaard, H. G., Seinfeld, J. H., and Wennberg, P. O.: Peroxy radical chemistry and $\mathrm{OH}$ radical production during the $\mathrm{NO}_{3}$-initiated oxidation of isoprene, Atmos. Chem. Phys., 12, 7499-7515, doi:10.5194/acp-12-74992012, 2012.

Lelieveld, J., Butler, T. M., Crowley, J. N., Dillon, T. J., Fischer, H., Ganzeveld, L., Harder, H., Lawrence, M. G., Martinez, M., Taraborrelli, D., and Williams, J.: Atmospheric oxidation capacity sustained by a tropical forest, Nature, 452, 737-740, 2008.

Lockwood, A. L., Shepson, P. B., Fiddler, M. N., and Alaghmand, M.: Isoprene nitrates: preparation, separation, identification, yields, and atmospheric chemistry, Atmos. Chem. Phys., 10, 6169-6178, doi:10.5194/acp-10-6169-2010, 2010.

Madronich, S.: UV radiation in the natural and perturbed atmosphere, in Environmental Effects of Ultraviolet Radiation, edited by: Tevini, M., 17-69, Lewis, Boca Raton, Florida, 1993.

Mao, J., Paulot, F., Jacob, D. J.,Cohen, R. C. , Crounse, J. D., Wennberg, P. O., Keller, C. A., Hudman, R. C., Barkley, M. P., and Horowitz, L. W.: Ozone and organic nitrates over the eastern United States: Sensitivity to isoprene chemistry, J. Geophys. Res., 118, 11256-11268, doi:10.1002/jgrd.50817, 2013.

Messaadia, L., El Dib, G., Ferhati, A., Roth, E., and Chakir, A.: Gas phase UV absorption cross-sections for a series of hydroxycarbonyls, Chem. Phys. Lett., 529, 16-22, 2012.

Neeb, P.: Structure-Reactivity based estimation of the rate constants for hydroxyl radical reactions with hydrocarbons, J. Atmos. Chem., 35, 295-315, 2000.

Orlando, J. J. and Tyndall, G. S.: Mechanism for the reaction of $\mathrm{OH}$ with two unsaturated aldehydes: Crotonaldehyde and acrolein, J. Phys. Chem., 106, 12252-12259, 2002.

Orlando, J. J. and Tyndall, G. S.: Laboratory studies of organic peroxy radical chemistry: an overview with emphasis on recent issues of atmospheric significance, Chem. Soc. Rev., 41, 62946317, 2012.

Orlando, J. J., Tyndall, G. S., and Paulson, S. E.: Mechanism of the $\mathrm{OH}$-initiated oxidation of methacrolein, Geophys. Res. Lett., 26, 2191-2194, 1999.
Park, J., Jongsma, C. G.,Zhang, R., and North, S. W.: OH/OD initiated oxidation of isoprene in the presence of $\mathrm{O}_{2}$ and $\mathrm{NO}$, J. Phys. Chem., 108, 10688-10697, 2004.

Paulot, F., Crounse, J. D., Kjaergaard, H. G., Kroll, J. H., Seinfeld, J. H., and Wennberg, P. O.: Isoprene photooxidation: new insights into the production of acids and organic nitrates, Atmos. Chem. Phys., 9, 1479-1501, doi:10.5194/acp-9-1479-2009, 2009.

Paulot, F., Henze, D. K., and Wennberg, P. O.: Impact of the isoprene photochemical cascade on tropical ozone, Atmos. Chem Phys., 12, 1307-1325, doi:10.5194/acp-12-1307-2012, 2012.

Peeters, J., Boullart, W., Pultau, V., Vandenberk, S., and Vereecken, L.: Structure-Activity Relationship for the addition of $\mathrm{OH}$ to (poly)alkenes: Site-specific and total rate constants, J. Phys. Chem., 111, 1618-1631, 2007.

Peeters, J., Nguyen, T. L., and Vereecken, L.: $\mathrm{HO}_{\mathrm{x}}$ radical regeneration in the oxidation of isoprene, Phys. Chem. Chem. Phys., 11, 5935-5939, doi:10.1039/b908511d, 2009.

Peeters, J. and Müller, J.-F.: $\mathrm{HO}_{\mathrm{x}}$ radical regeneration in isoprene oxidation via peroxy radical isomerisations. II: Experimental evidence and global impact, Phys. Chem. Chem. Phys., 12, 1422714235, doi:10.1039/C0CP00811G, 2010.

Pérez, I. M., LaFranchi, B. W., and Cohen, R. C.: Nitrogen oxide chemistry in an urban plume: investigation of the chemistry of peroxy and multifunctional organic nitrates with a Lagrangian model, Atmos. Chem. Phys. Discuss., 9, 27099-27165, doi:10.5194/acpd-9-27099-2009, 2009.

Perring, A. E., Pusede, S. E., and Cohen, R. C.: An observational perspective on the atmospheric impacts of alkyl and multifunctional nitrates on ozone and secondary organic aerosol, Chem. Reviews, 113, 5848-5870, doi:10.1021/cr300520x, 2013.

Pinho, P., Pio, C., and Jenkin, M.: Evaluation of isoprene degradation in the detailed tropospheric chemical mechanism, MCM v3, using environmental chamber data, Atmos. Environ., 39, 13031322, 2005.

Roberts, J. M. and Fajer, R. W.: UV absorption cross sections of organic nitrates of potential atmospheric importance and estimation of atmospheric lifetimes, Environ. Sci. Technol. 23, 945951, 1989.

Sander, S. P., Abbatt, J., Barker, J. R., Burkholder, J. B., Friedl, R. R., Golden, D. M., Huie, R. E., Kolb, C. E., Kurylo, M. J., Moortgat, G. K., Orkin, V. L., and Wine, P. H.: Chemical Kinetics and Photochemical Data for Use in Atmospheric Studies, Evaluation number 17, NASA Panel for data evaluation, JPL Publication 10-6, Jet Propulsion Laboratory, Pasadena, http: //jpldataeval.jpl.nasa.gov (last access: 10 March 2014), 2011

Ren, X., Olson, J. R., Crawford, J. H., Brune, W. H., Mao, J., Long,R. B., Chen, Z., Chen, G., Avery, M. A., Sachse, G. W., Barrick, J. D., and Diskin, G. S., Huey, L. G., Fried, A., Cohen, R. C., Heikes, B., Wennberg, P. O., Singh, H. B., Blake, D. R., and Shetter, R. E.: $\mathrm{HO}_{x}$ chemistry during INTEX-A 2004: Observation, model calculation, and comparison with previous studies, J. Geophys. Res., 113, D05310, doi:10.1029/2007JD009166, 2008.

Sandu, A. and Sander, R.: Technical note: Simulating chemical systems in Fortran90 and Matlab with the Kinetic PreProcessor KPP-2.1, Atmos. Chem. Phys., 6, 187-195, doi:10.5194/acp-6187-2006, 2006.

Saunders, S. M., Jenkin, M. E., Derwent, R. G., and Pilling, M. J.: Protocol for the development of the Master Chemical Mech- 
anism, MCM v3 (Part A): tropospheric degradation of nonaromatic volatile organic compounds, Atmos. Chem. Phys., 3, 161-180, doi:10.5194/acp-3-161-2003, 2003.

Suarez-Bertoa, R., Picquet-Varrault, B., Tamas, W., Pangui, E., and Doussin, J.-F.: Atmospheric fate of a series of carbonyl nitrates: photolysis frequencies and $\mathrm{OH}$-oxidation rate constants, Environ. Sci. Technol., 46, 12502-12509, 2012.

Vereecken, L. and Peeters, J.: Decomposition of substituted alkoxy radicals - part I: a generalized structure-activity relationship for reaction barrier heights, Phys. Chem. Chem. Phys., 11, 90629074, 2009.
Wolfe, G. M., Crounse, J. D., Parrish, J. D., St. Clair, J. M., Beaver, M. R., Paulot, F., Yoon, T. P., Wennberg, P. O., and Keutsch, F. N.: Photolysis, $\mathrm{OH}$ reactivity and ozone reactivity of a proxy for isoprene-derived hydroperoxyenals (HPALDs), Phys. Chem. Chem. Phys., 14, 7276-7286, 2012.

Xie, Y., Paulot, F., Carter, W. P. L., Nolte, C. G., Luecken, D. J., Hutzell, W. T., Wennberg, P. O., Cohen, R. C., and Pinder, R. W.: Understanding the impact of recent advances in isoprene photooxidation on simulations of regional air quality, Atmos. Chem. Phys., 13, 8439-8455, doi:10.5194/acp-13-8439-2013, 2013. 